\title{
APRESENTAÇÃO DO DOSSIÊ "TRABALHO, EDUCAÇÃO E POLÍTICAS PÚBLICAS"
}

\author{
PRESENTATION OF THE DOSSIER \\ "WORK, EDUCATION AND PUBLIC POLICY"
}

\author{
PRESENTACIÓN DEL DOSSIER \\ "TRABAJO, EDUCACIÓN Y POLÍTICA PÚBLICA"
}

\begin{abstract}
Aparecida Neri de Souza'
O dossiê Trabalho, Educação e Políticas Públicas reúne um conjunto de artigos que enfocam as relações entre trabalho e educação numa perspectiva analítica da sociologia da educação. Os temas de pesquisa e as análises apresentadas se inscrevem em problemáticas teóricas e metodológicas que repõe as necessidades de aprofundamento de estudos sobre as relações entre as desigualdades sociais e a educação, problema central nos estudos sociológicos.

O campo da sociologia da educação tem privilegiado o estudo da escola como espaço educativo (SPÓSITO, 2007, p. 19), entretanto, os problemas abordados têm se alargado para temáticas sobre as relações entre escolarização, formação, emprego e trabalho. Para além das questões conjunturais, revela-se uma problemática relevante para a compreensão da complexidade dos processos sociais de formação dos jovens e trabalhadores, pois "as análises de determinadas dimensões da realidade social, a exemplo do trabalho e da educação, não podem ser tratadas de forma dicotômica" (SOUZA, 2012, p. 83). Nesta chave analítica este dossiê foi organizado.

Os autores e textos privilegiaram a apresentação de resultados de pesquisas empíricas sem que a reflexão teórica tenha sido negligenciada. Eles confrontam as

\footnotetext{
${ }^{1}$ Doutora em Educação pela Universidade Estadual de Campinas (UNICAMP), com pós-doutoramento em Sociologia do Trabalho pela Université Paris 10, Nanterre, França, Laboratoire Genre, Travail et Mobilités (GTM). Atua como professora de Sociologia da Educação no Departamento de Ciências Sociais e Educação (DECISE) da UNICAMP, onde integra o quadro docente do Programa de Pós-Graduação em Educação. É líder do Grupo de Estudos e Pesquisas sobre Educação e Diferenciação Sociocultural (GEPEDISC). Tem experiência na área de Educação, com ênfase em Sociologia do Trabalho Docente, atuando principalmente nos seguintes temas: Trabalho e Formação Profissional; Relações de Trabalho no Setor Público (professores); Condições e Organização do Trabalho em Universidades; Trabalho, Políticas e Educação; Sociologia do Trabalho e Educação. É Coordenadora do GT-08 Trabalho e Educação da Associação Brasileira de Estudos do Trabalho. E-mail: anerisouza@uol.com.br
} 
questões teóricas sobre os sentidos sociais das políticas de formação de trabalhadores e trabalhadoras e nos permitem buscar novos questionamentos, inerentes à nossa atividade de pesquisa como sociólogos, pedagogos, historiadores, entre outros. No plano metodológico, as análises evidenciam a dimensão interdisciplinar da pesquisa sobre trabalho, educação e políticas.

O texto - "Currículo Integrado no chão da escola: concepções em disputa na sua materialidade" - resultante da pesquisa de mestrado de Rosane de Abreu Farias, com a orientação de Marise Nogueira Ramos, analisa conceitual e empiricamente a política de educação profissional pautada na concepção de formação integrada. Por meio da pesquisa empírica em uma escola técnica pública, é possível apreender a materialidade das concepções sobre educação profissional. $O$ artigo evidencia representações que os professores constroem sobre o sentido da educação de trabalhadores e trabalhadoras, o sentido social do trabalho é a dimensão econômica do mercado. Tal constatação permite às autoras indicar as possibilidades de superação de visões pragmáticas e imediatas sobre o processo de formação humana.

O artigo de Henrique Tahan Novaes - "A agenda agroecológica do MST e suas escolas de agroecologia: para além do ensino médio integrado da escola estatal?" -, também objeto de pesquisa empírica, apresenta as escolas de agroecologia do MST como espaço de resistência às agendas regressivas do capital, em especial das corporações transnacionais. $\mathrm{O}$ artigo destaca a disputa entre projetos societários em torno da formação de trabalhadores pelos movimentos sociais e o capital. O artigo dialoga com a pesquisa de Neila Pedrotti Drabach e Carmen Sylvia Vidigal Moraes sobre "O PRONATEC campo: entre o desenvolvimento da agricultura familiar e a formação de mão de obra para o agronegócio". As autoras também enfocam as disputas entre movimentos sociais e proprietários de terra sobre as políticas de formação de trabalhadores para o campo. Formar para a agricultura familiar ou formar para o agronegócio expressam disputas por hegemonia entre classes sociais, entre os interesses de reprodução do capital e de interesses da classe trabalhadora.

Os autores Marcelo Lima, Samanta Lopes Maciel e Michele Pazolini, no artigo "Políticas de Estado versus políticas de governo", argumentam, em diálogo com o artigo anterior, que a formulação de políticas para a formação de trabalhadores expressa coalização entre frações da burguesia e da classe trabalhadora. Haveria, segundo os autores, uma subordinação das políticas de Estado aos interesses do capital, em disputa pelos fundos públicos.

Maria Lucia Büher Machado aborda em "A orientação profissional nas escolas técnicas industriais no Brasil (1949-1963) a partir da CBAI" as disputas em torno da formação técnica profissional de trabalhadores no período de avanços do projeto de modernização brasileira por meio da intensificação da urbanização e industrialização do país. Os consensos construídos em torno da necessidade de formação de trabalhadores qualificados como indutores do processo de modernização são desvelados pela autora, de modo a indicar que as permanências de desigualdades de classe, gênero e formação de trabalhadores respondem a um projeto de ajustamento às demandas do capital.

Se os artigos anteriores colocaram em evidência disputas de projetos societários sobre as políticas governamentais para a formação de trabalhadores e trabalhadoras, o texto de Carla Regina Mota Alonso Diéguez - "Qualificação profissional e promoção do 
trabalho decente: uma relação possível"-, numa perspectiva da sociologia do trabalho, indagará sobre a funcionalidade dos programas de qualificação profissional para o mercado de trabalho a partir de estudo sobre os egressos desses programas. A relação entre qualificação, mercado de trabalho e qualidade do emprego aponta para a permanência das desigualdades sociais, de gênero e inserção no mercado de trabalho com empregos precários.

O artigo de Carla Ribeiro Santos sobre "A relação trabalho-educação na política socioeducativa do Estado do Rio de Janeiro", coloca em evidência o trabalho daqueles profissionais que atuam em instituições socioeducativas. Analisa não somente o trabalho destes profissionais como também o conteúdo da formação oferecida pelas instituições voltada para o empreendedorismo.

Na mesma chave analítica, segue a contribuição de Selma Borghi Venco e Beatriz Garcia Sanchez. Em seu artigo - "Supervisão de ensino paulista: managers da educação ou sujeitos da precariedade subjetiva" -, as autoras analisam o trabalho de profissionais que atuam na formação de outros trabalhadores. A partir da abordagem sobre os sentidos das mudanças no trabalho no setor público, concluem que há um processo de intensificação e precarização subjetiva dos trabalhadores estáveis e altamente qualificados.

Para encerrar o dossiê, o artigo - "Trabalho docente: do assalariamento à organização político sindical" - de Hugo Leonardo Fonseca da Silva realiza uma abordagem teórico-histórica sobre a transformação do ofício docente em trabalho assalariado. O texto repõe a discussão sobre o caráter de classe de professores e professoras. A construção do assalariamento docente se realiza sob determinadas circunstâncias históricas e sociais e permite colocar em evidência a concepção de Estado como patrão e o debate sobre a inserção de classe dos docentes. É nesse movimento teórico-histórico que o autor discute as lutas sociais mediadas pela organização dos trabalhadores docentes.

O dossiê aqui apresentado, ao tratar de um conjunto de pesquisas individuais ou coletivas no campo da sociologia do trabalho e da educação evidencia a heterogeneidade dos objetos de pesquisa. Os artigos refletem um movimento de elaboração de uma sociologia da sociologia da educação. Os problemas referentes à formação de trabalhadores e trabalhadoras em um país de capitalismo periférico permite compreender as complexas relações entre educação, emprego e trabalho e repercute na análise das dinâmicas de reprodução e de mudanças das dimensões políticas da educação. Esperamos contribuir, com este dossiê, para a abertura de novos campos de investigação e de produção teórica na sociologia para compreender os sentidos das mudanças no trabalho e na educação em sociedade de capitalismo periférico, como a brasileira.

\section{Referências}

SPOSITO, Marília Pontes. Uma perspectiva escolar no estudo sociológico da escola. In: PAIXAO, Lea Pinheiro; ZAGO, Nadir (Orgs.). Sociologia da educação. Pesquisa e realidade brasileira. Petrópolis: editora Vozes, 2007. 
SOUZA, Aparecida Neri de. Fronteiras entre duas esferas das atividades sociais: a educação e o trabalho. Educação e Sociedade. Campinas, volume 33, no. 118, p. 81-95, jan.-mar./2012. 